\title{
Factors predicting home delivery among women in Bosomtwe-Atwima-Kwanwoma district of Ghana: A case control study
}

\section{Moses L Nanang ${ }^{1}$,} Albert Atabila ${ }^{2}$

${ }^{1}$ Department of Global Outreach, American College of NurseMidwives (ACNM), Bolgatanga, ${ }^{2}$ International Programme on the Elimination of Child Labour, International Labour Organisation, Accra, Ghana

\section{Address for correspondence:} Mr. Moses L. Nanang, Midwifery Training School, Post Office Box 255, Bolgatanga, Upper East Region,

Ghana.

E-mail: liyobe@gmail.com

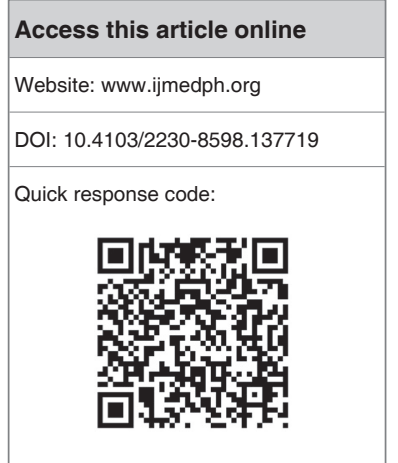

Background: Maternal mortality is unacceptably high in Ghana. This situation is attributed partly to non-availability of healthcare services and poor utilization of these services when they are available. More deliveries are still performed at home, and in many cases, without the supervision of trained attendants, despite the Ghana Government's fee exemption policy on maternal deliveries. The purpose of this study was to identify factors that predict home delivery among mothers. Materials and Methods: An unmatched case control study was conducted among mothers in the Bosomtwe-Atwima-Kwanwoma district of Ghana. A total of 114 mothers consisting of 54 cases and 60 controls participated in the study. A multi-stage sampling technique was used to select participants of the study. Data were collected using pre-tested questionnaires and analyzed using EPIINFO (3.3) and STATA (8.2) statistical software. Results: Mothers aged 31 years and above (AOR 3.00, 95\% CI: 1.16-7.74) and those with primary or no formal education (AOR $3.88,95 \% \mathrm{Cl}: 1.60-9.46$ ) were more likely to deliver at home. Also, the risk of home delivery for mothers with more antenatal care (ANC) clinic visits was less by 0.3 (30\%) (AOR $0.70,95 \% \mathrm{Cl}: 0.53-0.88$ ). Conclusion: The factors influencing home delivery among mothers were maternal ages of 31 years and above, primary or no formal education, and less than four ANC visits. Interventions aimed at improving female education, increasing the number of ANC visits, and providing counselling, follow-up, and support to older pregnant mothers are recommended to increase the number of women who deliver in healthcare facilities.

Key words: Ghana, maternal and child health, maternal factors, maternal mortality, place of delivery

\section{INTRODUCTION}

Maternal mortality is a very useful indicator of any country's health status. As a result, it has received both national and international attention over the years. In spite of this international attention and commitment of resources, high level of maternal mortality remains a nagging problem, especially in developing countries. For instance, of the estimated 585,000 maternal deaths occurring world-wide each year, about 99\% occur in developing countries, particularly Sub-Saharan Africa. This point is further demonstrated by the fact that in Africa, a woman's lifetime risk of dying from pregnancy and related complications is 1 in 16 as compared to 1 in 1,400 in Europe and 1 in 3,700 in North America. ${ }^{[1]}$

The high maternal mortality rates in developing countries have been attributed partly to the nonavailability of healthcare services and poor utilization of these services when they are available. The immediate medical causes of maternal death are similar for women all over the world: Postpartum hemorrhage, infection, toxemia, obstructed labor, and septic abortions. However, these diagnostic categories often conceal the underlying mechanisms and root causes of these deaths: Non-availability and low utilization of healthcare services. Access to quality care during pregnancy and especially at delivery is a crucial factor in explaining the disparity in maternal mortality and morbidity between the developing and the industrialized world. ${ }^{[2]}$ For example, in Sub-Saharan Africa, only $42 \%$ of deliveries are supervised by trained healthcare attendants, $50 \%$ in Asia, and $64 \%$ in the Middle East/North Africa. ${ }^{[3]}$

Studies have shown that women are most in need of skilled care during delivery and the immediate postpartum period, when about three-quarters of all maternal deaths occur. ${ }^{[3]}$ Traditional birth 
attendants, whether trained or untrained, can neither predict nor cope with serious complications. Thus, the single most critical intervention for safe motherhood is to ensure that a competent healthcare worker with basic emergency obstetric skills is present at every birth, and transport is available to a referral facility for obstetric care in case of an emergency.

In Ghana, maternal mortality is high, with figures in the range of 214-800 per 100,000 live births. ${ }^{[3]}$ It has been observed that more deliveries $(53 \%)$ still occur at home, ${ }^{[4]}$ and in many cases, without the supervision of trained attendants. Rural areas with poor road, communication, and healthcare facilities such as Bosomtwe-AtwimaKwanwoma district tend to fare the worse.

In an effort to increase the proportion of institutional deliveries, and thereby, safety of the birth process for mothers and their infants, the Government of Ghana introduced in 2003 the fee exemption policy on maternal deliveries in four most deprived regions of the country (northern, upper east, upper west, and central regions). ${ }^{[5]}$ The policy aims to remove financial barriers to accessing maternity services by women in these regions. Since October 2005, this policy has been extended to cover the rest of the country, including Bosomtwe-Atwima-Kwanwoma district.

However, evidence from the Upper East Region, one of the regions where this policy has been in operation since 2003, suggest no significant increase in institutional deliveries following the introduction of the policy. This reinforces the anecdotal belief that financial barrier is just one of several factors that influence the choice of place of delivery. A number of studies by Adofo, ${ }^{[6]}$ Ofori-Yeboah, ${ }^{[7]}$ and $G y a m f i^{[8]}$ examined the issue of home delivery elsewhere in Ghana. However, no study has been conducted in the Bosomtwe-Atwima-Kwanwoma district to identify the factors that influence the choice of delivery place, hence the need for such a study.

\section{MATERIALS AND METHODS}

The study was conducted among mothers in the BosomtweAtwima-Kwanwoma district. Bosomtwe-Atwima-Kwanwoma is one of the districts in the Ashanti region of Ghana. Kuntanase, the district capital is about $28 \mathrm{~km}$ from the city of Kumasi. The district shares common borders with Atwima, Ejisu-Juaben, and Kumasi Metropolis to the North; Asante-Akim North on the East; and Amansie- East and West on the South. The district covers an area of approximately $681.7995 \mathrm{sq} \mathrm{km}$, with a total population of 166,924 .

This was an unmatched case-control study. Cases were defined as mothers with children aged 2 years or less who delivered outside healthcare facilities, while controls were mothers with children aged 2 years or less who delivered in healthcare facilities (including maternity homes).

Since this study used the unmatched case-control study design, the following formula ${ }^{[9]}$ was used to determine the sample size:

$\underline{(\mathrm{U}+\mathrm{V})^{2}\{\mathrm{P} 1(100-\mathrm{P} 1)+\mathrm{P} 2(100-\mathrm{P} 2)\}}$

(P1-P2)
Where:

$\mathrm{U}=80 \%$ power $(0.842)$.

$\mathrm{V}=0.05$ significance (1.96).

P1 = Proportion of healthcare facility deliveries in the district $(63 \%) \cdot{ }^{[10]}$

$\mathrm{P} 2=$ Proportion of home deliveries in the district $(37 \%) \cdot{ }^{[10]}$

Using the above formula, a sample size of 54 was obtained for each of the two groups. This was rounded up to 60 each, making a total sample size of 120 mothers.

A multi-stage sampling technique was used. This involved random selection of two sub-districts (Foase and Amakom) out of five sub-districts by using the lottery method. Still employing the lottery method, three communities were further randomly selected from each of the two sub-districts. To obtain a sample frame, a census of all mothers with children aged 2 years or less was conducted in the six study communities. After the census, cases from the six communities were summed up to 123 . Each case was given a three digit code (001-123), which were then written on pieces of paper, folded, and placed in an opaque container. One folded paper was then picked from the container at random. The name that matched the code picked was noted and written down. The piece of paper was folded again and placed back into the container. Numbers that were picked more than once were also placed back into the container. This was to give all respondents equal chance of being selected. This process was repeated until all 60 cases were selected. This procedure was repeated to select the controls.

Data were collected by trained Research Assistants using structured questionnaires after pre-testing. The questionnaires were in three sections: Socio-demographic characteristics, obstetric characteristics, and healthcare service-related factors.

Data for the study were analyzed in three ways. First, frequency tables were used to present the variables of the study and Pearson's chi-square $\left(\chi^{2}\right)$ test was used to compare cases and controls. Second, bivariate analysis was done using cross-tabulations to determine association between the dependent variable (place of delivery) and various independent variables. Third, all explanatory variables that were significant in bivariate analysis were included in multivariate analysis involving the use of logistic regression. Categorical variables with three or more levels were converted into two dummy variables. Statistical softwares used were EPIINFO (3.3) and STATA (8.2).

\section{ETHICAL CLEARANCE}

The study received approval from the University of Ghana's School of Public Health. Also, the permission to carry out the study was obtained from both political and traditional authorities in the district and the communities where the study was done. The purpose of the study was explained to them. Verbal consent was obtained from all mothers 
who participated in the study. They were briefed on the rationale of the study and given the opportunity to opt out of the study at any stage, if they felt otherwise about the rationale of the study.

\section{RESULTS}

\section{Descriptive information of respondents}

Among the 120 samples chosen, 114 respondents (54 cases, 60 controls) were successfully interviewed, giving a response rate of $95 \%$. In terms of socio-demographic characteristics, 103 $(90.3 \%)$ respondents were in marital union; 64 (56.1\%) were 30 years old or younger; $63(55.3 \%)$ were educated to the junior high school level or higher; 58 (50.9\%) were engaged in petty trading or subsistence farming; and $78(68.4 \%)$ of them earned less than GHC 40.0 [Table 1]. Regarding obstetric characteristics, $86(75.4 \%)$ of the respondents had given birth to less than five children; $64(56.1 \%)$ visited antenatal care (ANC) clinic at least four times during their last pregnancy; and 67 (58.8\%) of them preferred lying during delivery. Concerning healthcare service-related factors, $61(53.5 \%)$ of the mothers indicated that delivery charges were not affordable; 58 (50.9\%) asserted that transportation was always available to the nearest healthcare facility in their community; $77(67.5 \%)$ rated the quality of care they received during delivery as poor; and $93(81.6 \%)$ rated attendants' attitude and/or behavior as good.

\begin{tabular}{|c|c|c|c|c|c|}
\hline \multirow[t]{2}{*}{ Variables } & \multicolumn{3}{|c|}{ Frequency (\%) } & \multirow[t]{2}{*}{$x^{2}$} & \multirow[t]{2}{*}{$P$-value } \\
\hline & $\begin{array}{l}\text { Cases } \\
n=54\end{array}$ & $\begin{array}{c}\text { Controls } \\
n=60\end{array}$ & $\begin{array}{c}\text { Total } \\
n=114\end{array}$ & & \\
\hline \multicolumn{6}{|l|}{ Socio-demographic characteristics } \\
\hline Marital status & & & & 0.0179 & $>0.05$ \\
\hline Married & $49(90.7)$ & $54(90.0)$ & $103(90.3)$ & & \\
\hline Single/divorced/separated/widowed & $5(9.3)$ & $6(10.0)$ & $11(9.7)$ & & \\
\hline Age of mother & & & & 12.4011 & $<0.001$ \\
\hline$\leq 30$ years & $21(38.9)$ & $43(71.7)$ & $64(56.1)$ & & \\
\hline$\geq 31$ years & $33(60.1)$ & $17(28.3)$ & $50(43.9)$ & & \\
\hline Level of education & & & & 19.958 & $<0.0001$ \\
\hline No education/primary & $36(66.7)$ & $15(25.0)$ & $51(44.7)$ & & \\
\hline Junior high school or higher & $18(33.3)$ & $45(75.0)$ & $63(55.3)$ & & \\
\hline Occupation & & & & 0.328 & $>0.05$ \\
\hline Housewife & $25(46.3)$ & $31(51.7)$ & $56(49.1)$ & & \\
\hline Petty trading/subsistence farming & $29(53.7)$ & $29(48.3)$ & $58(50.9)$ & & \\
\hline Monthly income (GHC) & & & & 0.1462 & $>0.05$ \\
\hline$<40.0$ & $36(66.7)$ & $42(70.0)$ & $78(68.4)$ & & \\
\hline 40.0 and above & $18(33.3)$ & $18(30.0)$ & $36(31.6)$ & & \\
\hline \multicolumn{6}{|l|}{ Obstetric characteristics } \\
\hline Parity & & & & 6.2497 & 0.01 \\
\hline 1-4 children & $35(64.8)$ & $51(85.0)$ & $86(75.4)$ & & \\
\hline $5+$ children & $19(35.2)$ & $9(15.0)$ & $28(24.6)$ & & \\
\hline Number of ANC visits & & & & 8.611 & $<0.01$ \\
\hline $1-3$ & $32(59.3)$ & $18(30.0)$ & $50(43.9)$ & & \\
\hline 4 and above & $22(40.7)$ & $42(70.0)$ & $64(56.1)$ & & \\
\hline Preferred delivery position & & & & 6.5904 & 0.01 \\
\hline Sitting/squatting & $29(53.7)$ & $18(30.0)$ & $47(41.2)$ & & \\
\hline Lying (supine) & $25(46.3)$ & $42(70.0)$ & $67(58.8)$ & & \\
\hline \multicolumn{6}{|l|}{ Health service-related characteristics } \\
\hline Delivery charges & & & & 6.6986 & 0.01 \\
\hline Affordable & $18(33.3)$ & $34(56.7)$ & $52(45.6)$ & & \\
\hline Not affordable & $36(66.7)$ & $25(41.7)$ & $61(53.5)$ & & \\
\hline Attendant attitude and/or behavior & & & & 2.3236 & $>0.05$ \\
\hline Good & $46(85.2)$ & $47(78.3)$ & $93(81.6)$ & & \\
\hline Poor & $5(9.3)$ & $12(20.0)$ & $17(14.9)$ & & \\
\hline Quality of care & & & & 3.2883 & $>0.05$ \\
\hline Good & $13(24.1)$ & $24(40.0)$ & $37(32.5)$ & & \\
\hline Poor & $41(75.9)$ & $36(60.0)$ & $77(67.5)$ & & \\
\hline Availability of transport to healthcare facility & & & & 18.5336 & $<0.0001$ \\
\hline Always available & $16(29.6)$ & $42(70.0)$ & $58(50.9)$ & & \\
\hline Sometimes available or not available at all & $38(70.4)$ & $18(30.0)$ & $56(49.1)$ & & \\
\hline
\end{tabular}


Table 1 reveals that cases and controls differed significantly in terms of the age of mother, level of mother's education, parity, number of ANC visits, availability of transport, preferred delivery position, and delivery charges $(P \leq 0.01)$. However, there was no significant difference between cases and controls in terms of marital status, occupation, monthly income, attendant behavior and/or attitude, and quality of care $(P>0.05)$.

\section{Bivariate analysis}

Table 2 shows that in the bivariate analysis, the following explanatory factors were significantly associated with the place of delivery: Age of mother, level of mother's education, parity, number of ANC visit, availability of transport, preferred delivery position, and delivery charges $(P \leq 0.01)$. However, marital status, occupation, monthly income, attendant behavior and/or attitude, and quality of care were not significantly related to place of delivery $(P>0.05)$. Mothers aged 31 years and above, those with primary or no education, and those with five or more children were more likely to deliver at home. Also, mothers who visited ANC clinics for less than four times, those with transportation challenges to healthcare facilities, those who preferred sitting/squatting position during delivery and those who felt delivery charges were not affordable were more likely to deliver at home.

\section{Multivariate analysis}

From Table 3, explanatory variables that remained significant in multivariate analysis were age of mother, level of education of mother, and number of ANC visits $(P<0.05)$. Mothers whose ages were 31 years and above were 3 times (AOR 3.00, 95\% CI: 1.167.74) more likely to deliver at home, compared with mothers aged 30 years or less. Mothers with primary or no formal education were about four times more likely to deliver at home than those educated to junior high school level or higher (AOR 3.88, 95\% CI: 1.60-9.46). Regarding ANC visits, the risk of home delivery for mothers with more (at least four) ANC visits reduced by 0.3 (30\%), compared with those with fewer (1-3) ANC visits (AOR 0.70, 95\% CI: 0.53-0.88).

\section{DISCUSSION}

Place of delivery was significantly influenced by the age of mothers in both bivariate and multivariate analyses. Mothers aged 31 years and above were three times more likely to deliver at home compared with those aged 30 years or less. A similar finding was observed in Saudi Arabia by Al-Nahedh ${ }^{[11]}$ and elsewhere in Ghana. ${ }^{[4]}$ The reason for this could be because many older women in Africa regard themselves as experts in matters concerning childbirth. It would therefore seem ridiculous to them to go to the healthcare facilities to be delivered by staff they consider far younger and less experienced than themselves. Also, older women might have gotten used to home delivery by their mothers and are, therefore, more likely to repeat such practice. However, the finding of this study is at variance with the observation in South Africa, ${ }^{[12]}$ where more teenagers chose home delivery because they were often scolded and "preached" to by care providers for becoming pregnant at an early age.

\begin{tabular}{|c|c|c|}
\hline Variables & OR $(95 \% \mathrm{Cl})$ & $P$-value \\
\hline Marital status & & $>0.05$ \\
\hline Married & 1 & \\
\hline Single/divorced/separated/widowed & $0.92(0.26-3.19)$ & \\
\hline Age of mother & & $<0.001$ \\
\hline$\leq 30$ years & 1 & \\
\hline$\geq 31$ years & $4.0(1.82-8.71)$ & \\
\hline Level of education & & $<0.0001$ \\
\hline No education/primary & $6.0(2.66-13.53)$ & \\
\hline Junior high school or higher & 1 & \\
\hline Occupation & & $>0.05$ \\
\hline Housewife & 1 & \\
\hline Petty trading/subsistence farming & $0.81(0.39-1.68)$ & \\
\hline Monthly income (GHC) & & $>0.05$ \\
\hline$<40.0$ & $0.86(0.39-1.89)$ & \\
\hline 40.0 and above & 1 & \\
\hline Parity & & 0.01 \\
\hline 1-4 Children & 1 & \\
\hline $5+$ Children & $3.08(1.25-7.58)$ & \\
\hline Number of ANC visits & & $<0.01$ \\
\hline $1-3$ & $3.12(1.44-6.72)$ & \\
\hline 4 and above & 1 & \\
\hline Preferred delivery position & & 0.01 \\
\hline Sitting/squatting & $2.71(1.25-5.84)$ & \\
\hline Lying (supine) & 1 & \\
\hline Delivery charges & & 0.01 \\
\hline Affordable & 1 & \\
\hline Not affordable & $2.72(1.26-5.85)$ & \\
\hline Attendant attitude and/or behavior & & $>0.05$ \\
\hline Good & 1 & \\
\hline Poor & $0.43(0.14-1.30)$ & \\
\hline Quality of care & & $>0.05$ \\
\hline Good & 1 & \\
\hline Poor & $2.1(0.94-4.72)$ & \\
\hline $\begin{array}{l}\text { Availability of transport to } \\
\text { healthcare facility }\end{array}$ & & $<0.0001$ \\
\hline Always available & 1 & \\
\hline $\begin{array}{l}\text { Sometimes available or not } \\
\text { available at all }\end{array}$ & $5.54(2.48-12.38)$ & \\
\hline
\end{tabular}

\begin{tabular}{lcc}
\multicolumn{4}{l}{ Table 3: Predictors of place of delivery } \\
\hline \multicolumn{1}{l}{ Variable } & AOR $(95 \% \mathrm{Cl})$ & $P$-value \\
\hline Age of mother & 1 & $<0.05$ \\
$\quad \leq 30$ years & $3.00(1.16-7.74)$ & \\
$\geq 31$ years & $3.88(1.60-9.46)$ & \\
Level of education & 1 & \\
$\quad$ No education/primary & & \\
$\quad$ Junior high school or higher & 0.01 \\
Number of ANC visits & $0.70(0.53-0.88)$ & \\
$1-3$ & 1 & \\
4 and above &
\end{tabular}

Educational level of mothers was also a predictor of the choice of place of delivery. Mothers with primary or no formal education were about four times more likely to deliver at home than those educated to junior 
high school level or higher. This finding compares well with those of other similar studies in Uganda, ${ }^{[13]}$ Malawi,,${ }^{[14]}$ Kenya, ${ }^{[15]}$ Nepal, ${ }^{[16]}$ and Saudi Arabia, ${ }^{[1]}$ and shows that low level of mother's education was a significant factor for home delivery. The likely explanation for the finding of this study could be because mothers with more years of education are more aware of the importance of delivering in a healthcare facility. They are also in a better position to appreciate health education messages and act on them. In addition, women with more years of education have high self-confidence and feel comfortable delivering in healthcare facilities.

Another predictor of the choice of place of delivery identified in this study was the number of ANC visits by mothers. Generally, obstetricians recommend 12-13 visits per pregnant woman beginning from the first trimester. However, in light of myriad constraints confronting the healthcare sector, especially in developing countries, the World Health Organization (WHO) ${ }^{[3]}$ has set a minimum of four visits by every pregnant woman. In this study, mothers with at least four ANC visits were about 30\% less likely to deliver at home compared to those with less than four ANC visits. This finding is in conformity with another study in Kenya, which found that the probability of a home delivery was 9.2 times for those who received no ANC compared to those who had at least seven or more antenatal consultations. ${ }^{[15]}$ ANC visits not only make it possible for the pregnant woman to be examined, counselled, and given immunization, but also provide opportunities to effectively establish and sustain a client-provider rapport. Generally, the more clients interact with service providers, the more they are likely to trust, confide in them, and practice the medical advice given to them.

Although income, ${ }^{[4]}$ occupation, parity, ${ }^{[13]}$ preferred delivery position, ${ }^{[17]}$ delivery charges, ${ }^{[18]}$ Attendant attitude and/or behavior, ${ }^{[-8,19]}$ quality of care, ${ }^{[17,20]}$ and availability of transport to healthcare facility ${ }^{[6-8,18]}$ have been found to be significant predictors of the choice of place of delivery in other places, these factors did not influence the place of delivery in this study.

Due to the research design used, recall bias could be a possible limitation to this study. However, pre-testing of the questionnaires, adequate training given to data collectors, and their supervision could minimize this effect.

\section{CONCLUSION}

Maternal age of 30 years or less, educated to junior high school level or higher, and attending ANC clinic at least four times were factors that significantly influenced delivery in healthcare facilities. Implementing interventions aimed at improving female education, increasing the number of ANC visits, and providing counselling, follow-up, and support to older pregnant mothers are recommended to increase the number of women who deliver in healthcare facilities.

\section{ACKNOWLEDGMENTS}

We are grateful to Dr Kofi Oduro Asante (Senior Lecturer, University of Ghana School of Public Health, Legon) and Dr. Omar Ahmad (Senior Lecturer, University of Ghana School of Public Health, Legon) for their advice and suggestions on this study. Our gratitude also goes to Dr. Agartha Bonney (District Director of Health Services, Bosomtwe-AtwimaKwanwoma) for her immense support during the data collection exercise.

\section{REFERENCES}

1. Family Care International. Sexual and Reproductive Health briefing cards. New York: Family Care International; 2000.

2. Wagle RR, Sabroe S, Nielsen BB. Socioeconomic and physical distance to the maternity hospital as predictors for place of delivery: An observation study from Nepal. BMC Pregnancy Childbirth 2004;4:8.

3. United Nations Children's Education Fund (UNICEF). Maternal Care. 2001. Available from: http://www.unicef.org/specialsession/about/sgreportpdf/11_ MaternalCare_D7341Insert English.pdf ¡[Last accessed on 2005 Feb 25].

4. Ghana Statistical Service (GSS), Noguchi Memorial Institute for Medical Research (NMIMR), and ORC Macro 2004. Ghana Demographic and Health Survey 2003. Calverton, Maryland: GSS, NMIMR, ORC Macro p. 144.

5. Ministry of Health. Guidelines for Implementing the Exemption Policy on Maternal Deliveries. Ghana: Ministry of Health Accra; 2004.

6. Adofo AO. Factors affecting utilization of maternity Services in Yendi District. MPH Dissertation, School of Public Health. Ghana: University of Ghana; 1999.

7. Ofori-Yeboah Y. A study of the characteristics of women opting for Home or Institutional delivery after antenatal care in the Wassa-West District. MPH dissertation, School of Public Health. Ghana: University of Ghana; 2000.

8. Gyamfi S. Why are women in Dangme West District not delivering in the health institutions? MPH dissertation, School of Public Health. Ghana: University of Ghana; 2001.

9. Varkevisser CM, Pathmanathan I, Brownlee A. Designing and conducting Health systems research. Canada: International Research Development Centre; 2003;Vol. 1 p. 11.

10. Bosomtwe-Atwima-Kwanwoma District Health Administration. 2004 Annual Report. Ashanti Region, Ghana. 2005. p. 15.

11. Al-Nadhedh NN. Factors affecting the choice of maternal and child health services in a rural area of Saudi Arabia. East Mediterr Health J 1995;1:261-9.

12. Fonn S, Xaba M, Tint KS, Conco D, Varkey S. Reproductive health services in South Africa: From rhetoric to implementation. Reprod Health Matters 1998;6:22-32.

13. Ministry of finance and economic planning. Uganda Demographic and Health Survey. Calverton, Maryland, USA: Uganda and Macro International Inc.; 1995.

14. Lule GS, Ssembatya M. Intention to deliver and delivery outcome. In: Roberts $\mathrm{JH}$ and Vlassoff $\mathrm{C}$, editors. The female client and the health-care provider. Ottawa, Canada: International Development Research Centre [IDRC]; 1995. p. 79-90.

15. Magadi M, Diamond I, Rodrigues R. The determinants of delivery care in Kenya. Soc. Biol 2002;47:164-88.

16. Bolam A, Manandhar DS, Shrestha P, Ellis M, Malla K, Costello AM. Factors affecting home delivery in Kathmandu Valley, Nepal. Health Policy Plan 1998;13:152-8.

17. Kyomuhendo GB. Low use of rural maternity services in Uganda: Impact of Women's status, traditional beliefs and limited resources. In: Marge B, editor. Reproductive Health Matters Vol. 11, No. 21.Oxford, UK: Blackwell Science Ltd; 2003.

18. Biego G, Curtis S, Raggers H, Kapiga S, Ngallaba S. Survey on adult and childhood mortality, Tanzania. Calverton, MD: Macro International; 1995.

19. Wilson JB, Collison AH, Richardson D, Kwofie G, Senah KA, Tinkorang EK. The maternity waiting concept: The Nsawam, Ghana experience. Int J Gynaecol Obstet 1997;59(Supp 2):165-72.

20. United Nations Fund for Population Activities. Ensuring skilled attendance at births. Available from: http://www.unfpa.org/mothers/skilled_att.htm [Last accessed on 2005 Feb 08].

How to cite this article: Nanang ML, Atabila A. Factors predicting home delivery among women in Bosomtwe-Atwima-Kwanwoma district of Ghana: A case control study. Int J Med Public Health 2014;4:287-91.

Source of Support: Nil, Conflict of Interest: None declared. 